\title{
Chapter 2
}

\section{Metal-Organic Frameworks and their Composites for the Development of Electrochemical Sensors for Environmental Applications}

\author{
Ankit Kumar Singh and Ida Tiwari* \\ Department of Chemistry, (Centre of Advanced Study), Institute of Science, Banaras Hindu \\ University, Varanasi, India \\ idatiwari@bhu.ac.in
}

\begin{abstract}
The demand for accurate monitoring of environmental pollutants and their control has increased the need to develop some novel sensing techniques with high accuracy and lower limit of detection. Number of electrochemical sensors have been developed which can provide such platform for the determination of variety of chemical as well as biological pollutants. Metal-organic frameworks (MOFs) synthesized by coordinating the metal ions with the organic moieties are extensively used in the electrochemical sensing. Detection and removal of heavy metal ions and several inorganic as well as organic ions can be done by using electrochemical sensors based on MOFs and their composites. MOFs are used for constructing highly sensitive and reliable electrochemical sensor because MOFs are highly porous and have large surface area that helps in concentrating the analyte which results in strong signal intensity and higher sensitivity. Here advantages of MOFs and their composites in the construction of electrochemical sensors as well as their applications in the determination of several environmental contaminants are discussed.
\end{abstract}

Keywords

Metal-Organic Frameworks, Electrochemical Sensor, Environmental Applications, Sensing

\section{Contents}

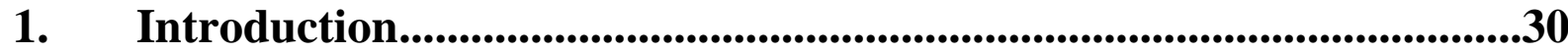

2. Synthesis of MOFs and MOF composites .................................................33 


\section{Sensors based on MOF for environmental applications........................34}

\section{Electrochemical sensor based on MOF for} environmental applications.

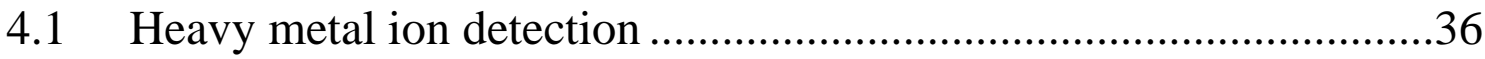

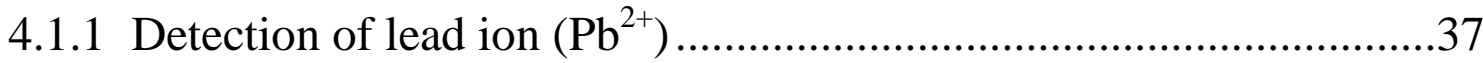

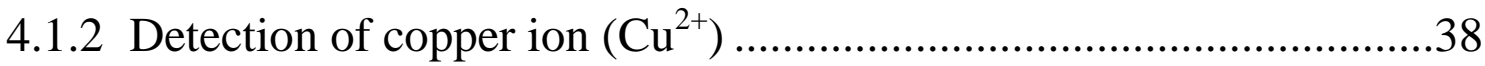

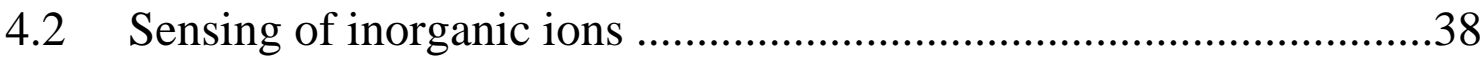

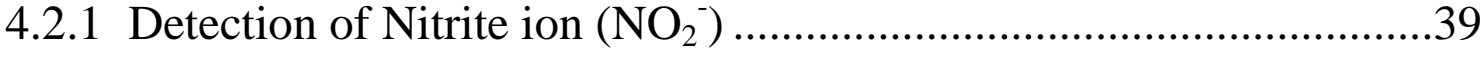

4.3 Sensing of organic compounds......................................................

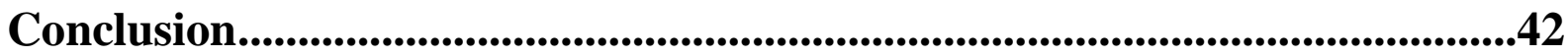

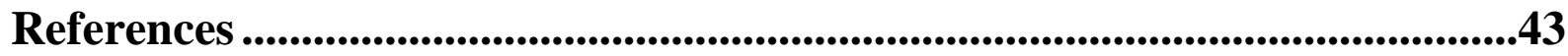

\section{Introduction}

Metal-organic frameworks (MOFs) are porous crystalline material having large internal surface area, uniform but adjustable cavity and reasonable thermal and mechanical stability (Fig. 1) [1-9]. They show various applications in different fields such as catalysis [10-25], gas separation, gas storage [26-38], sensing [39-42], drug delivery [43, 44], luminescence $[45,46]$, and other which are based on pore size and shape as well as those where host-guest interactions are involved. In addition to these applications, in recent years fascinating applications of MOFs in supercapacitors, batteries, fuel cell, hydrogen evolution reaction (HER), oxygen evolution reaction (OER) and oxygen reduction reaction (ORR) are reported [2].

The concepts related to MOFs was firstly introduced by Yaghi group [2] in 1995 and they provided MOF structure (MOF-5 based on Zinc) in 1999 which have large surface area of about $2900 \mathrm{~m}^{2} \mathrm{~g}^{-1}$ and having porosity of $60 \%$. After this large numbers of MOFs were also reported that showed structural, magnetic, optical, catalytic and electrical properties based on the choice of metal ions and organic ligands. .

Recently several investigations have been performed in order to determine the potential of MOF as sensors. However, in order to achieve certain potential as a sensor, MOF may require some functionalization. Three different pathways have been identified in order to create some modifications in the MOFs so that it can be utilized in various fields [47]. The first method involves modification in the specific organic ligand or doping in the metal ions within the framework of the MOFs. Generally lanthanide metal ions are involved in doping so that luminescent MOFs are created for optical sensing [48]. The 
second approach is post-synthesis modification (PSM), which involves the organic moiety with functional groups that can be used for subsequent chemical grafting. For the preparation of single-crystal MOF, Kurmoo et al. [49] tried to design a trifunctional (carboxylate, imidazolate, and hydroxyethyl groups) tag and for the improvement in the gas uptake of the MOF two consecutive PSMs of elimination and bromination were performed. The third approach involves the synthesis of composites having multifunctionalities for molecular recognition and transduction of signal by entrapping of functional molecules and nanoparticles (NPs) within the framework. These three approaches form the principle for functioning of the MOF i.e. any changes of MOF properties on the basis of incoming guest could be measured as a sensing signal [47].

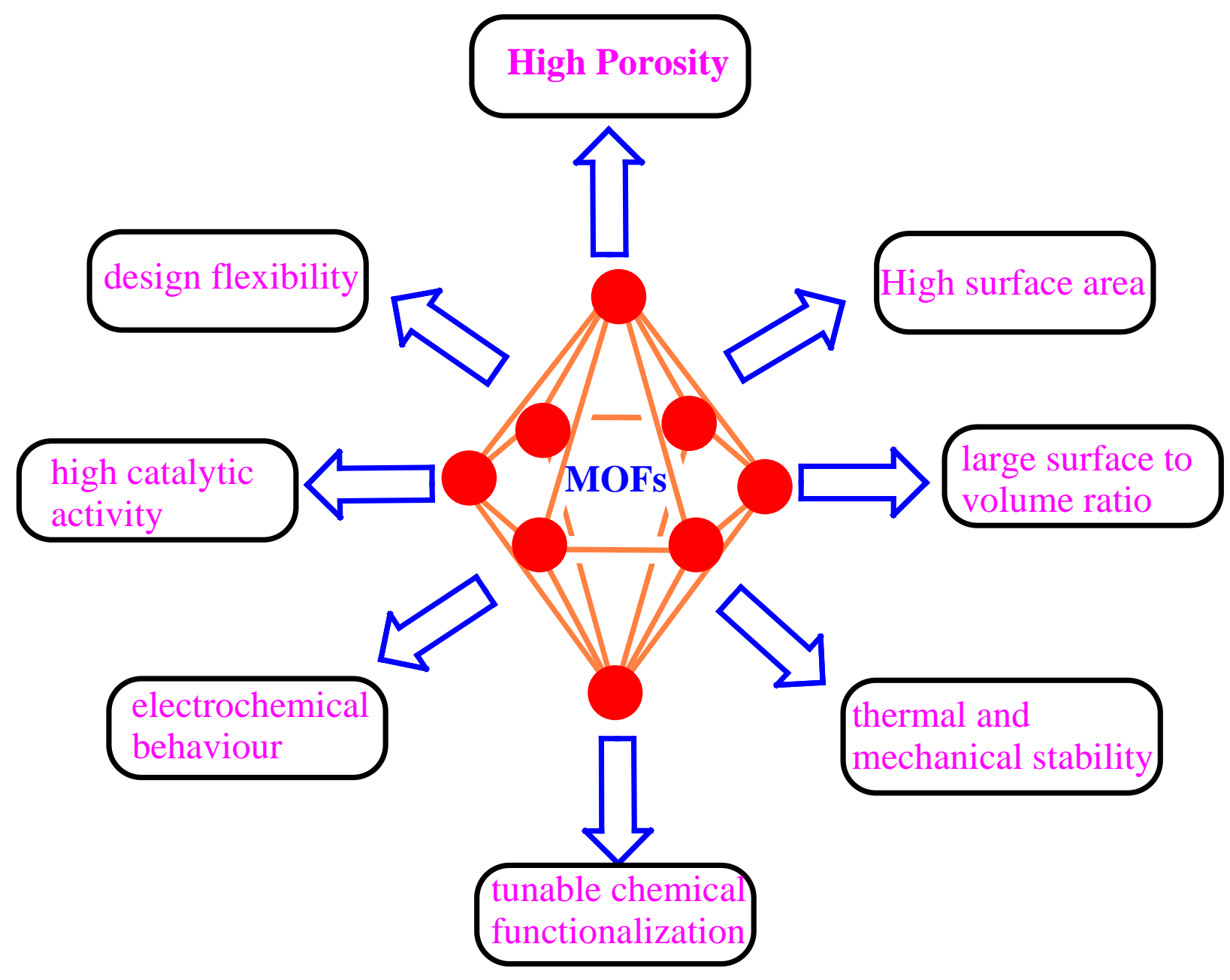

Figure 1. Useful properties of Metal-organic frameworks (MOFs) 
Environmental pollution due to emission and discharge of chemical pollutants have increased the demand for advanced chemical sensor devices however electrochemical sensors show great promise for this task. Metal-organic frameworks (MOFs) generally prepared by coordinating metal ions with organic ligands in suitable solvent are widely used in electrochemical sensing. But initially MOF materials were considered that they were generally not suitable for various electrochemical applications as they have poor electron conductive behavior. However various MOFs and MOF composites are used now-a-days in the manufacture of electrode material for rechargeable batteries and electrochemical sensors by making some modification in MOF so that its electron conductive behavior gets improved [50-52]. This can be achieved moreover by converting MOF to several nano structures, such as metal nanoparticles, porous carbon, metal oxides and their composites by treating with different methods. In these ways nanostructures may have maximum exposure of their active sites i.e. they have large surface area of MOF precursors and may exhibit good response as electrodes. Therefore the most important thing is to design MOFs and MOF composites with desired electrochemical behavior [1]. The efficient electrochemical signal can be achieved by preparing MOF with high redox activity and electrical conductivity. This can be achieved in large number of ways; one useful way is by the incorporation of several functional groups into MOFs so that it can be utilized for various applications in environmental cleaning [53,54].

The working of electrochemical sensor is based on the redox reactions of the analytes taking place in an electrochemical system. An electrochemical sensor consists of three components that are a working (or sensing) electrode, a counter electrode and usually a reference electrode as well. These electrodes are enclosed along with a liquid electrolyte [55-57]. Several modification can be done in working electrode for specific recognition and for determination of concentration of metal ions [58,59]. The presence of heavy metals as well as several inorganic and organic components as pollutant can cause the change of current, potential, capacitance, electrochemical impedance, electrochemiluminiscence and these changes can be utilized in their detection [60,61]. On the basis of these detection signals, the electrochemical sensing can be classified as amperometry, potentiometry, capacitance, electrochemical impedance and electrochemiluminiscent methods.

In the upcoming 50 years, the energy and environmental issues will rank top priorities among the various global issues. In order to satisfy the energy needs the fossil fuel can act as dominant source. However depletion of these resources are leading to several environmental hazards such as air pollution and global warming due to emission of several toxic gases such as methane, nitrous oxide, carbon monoxide, carbon dioxide and 
other gases having volatile organic compounds [62,63]. Some other environmental issues are related with the availability of fresh water because the industrial waste water causes severe problem and the water become polluted. Industrial effluents mainly contains heavy metals as well as some inorganic and organic pollutants that are responsible for the contamination of the fresh water and in this way living organisms on earth are suffering from the scarcity of fresh water [64].

Heavy metals are highly toxic and are considered as "Environmental health hazards".

These heavy metals are non-biodegradable and causes harm to human health and environment $[64,65]$. These heavy metals are easily accumulated in the biosphere and can enter the living organisms through the alimentary chain and in this way they can affect the human health [66]. Heavy metals can exert their toxic effect through bond formation with thiol group of proteins but when they enter the living cell can alter the biological lifecycle. Various heavy metals like mercury (Hg), cadmium (Cd), lead ( $\mathrm{Pb}$ ), chromium (Cr) and arsenic (As) are the most probable for causing most of the heavy metal-related diseases. But some of the heavy metals like iron, cobalt, zinc, copper, manganese, etc. are required by the living organisms in lower quantity however its presence at higher concentration causes various toxic effects [67-69]. For this purpose many nanomaterials such as porous carbon, transition metal oxides (TMOs), mixed TMOs, and transition-metal oxide-carbon (TMO@C) composites are studied so that they can be utilized in environmental cleaning due to their ability of detection of heavy metals [62]. However the researches performed in recent years have shown that a better result can be obtained by using MOF and their composites as an electrochemical sensor for the detection of several heavy metals, some inorganic and organic species as well as in their removal mechanism [70,71].

\section{Synthesis of MOFs and MOF composites}

Due to various applications of MOFs it becomes necessary to pay much attention on its synthesis. Extensive reviews have been published that cover partially or wholly several approaches for the synthesis of MOFs and their composites. Liquid phase synthesis of MOF is widely used which involve the mixing of separate solution of metal salt and ligand in a glass vial. This can also be done in one other way that is to a solid mixture of metal salt and ligand in glass vial solvent is added. A suitable solvent should be taken based on different aspects such as reactivity, solubility, redox potential, stability constant, etc. The solid phase synthesis has also been worked on as it is quick and easy in comparison to liquid phase synthesis however it shows several difficulties in obtaining single crystal and thereby in determining product structure which is quite easy in the case of liquid phase synthesis. The end result is formation of metal-organic frameworks by the 
interaction of metal ions or clusters with the organic moieties. (Fig. 2) These MOF formed may be one dimensional, two dimensional or three dimensional [72, 73].

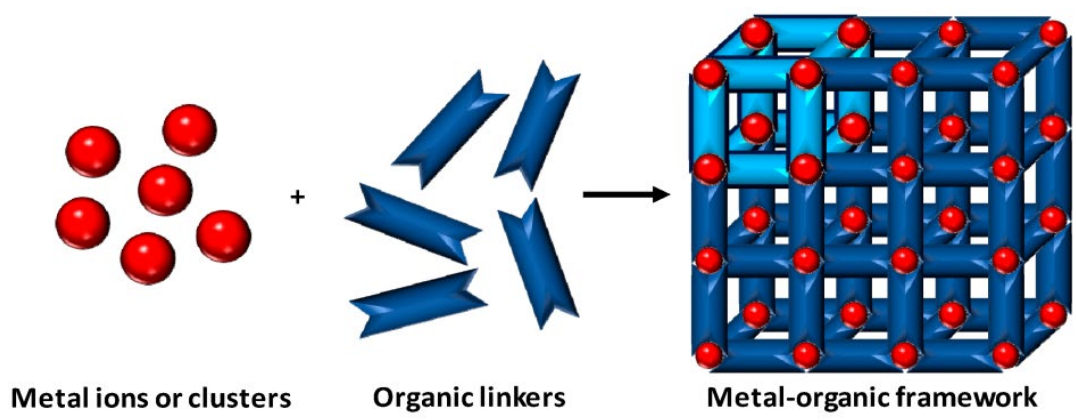

Figure 2. Scheme showing the formation of MOF by mixing metal ions or clusters with organic linkers in the presence of some suitable solvent [74].

Table 1. Different conditions required for various synthesis method.

\begin{tabular}{|c|c|c|c|c|c|}
\hline \multirow{2}{*}{ S.No. } & \multirow{2}{*}{ Synthesis Method } & \multicolumn{2}{|c|}{ Different conditions for synthesis } & \multirow{2}{*}{ References } \\
\cline { 3 - 5 } & Type of Energy & Time & $\begin{array}{c}\text { Temperature } \\
(\mathrm{K})\end{array}$ & \\
\hline 1. & Solvothermal & Thermal Energy & $48-96$ hours & $353-453$ & $62,72,73$ \\
\hline 2. & Microwave & $\begin{array}{c}\text { Microwave } \\
\text { Radiation }\end{array}$ & $\begin{array}{c}4 \text { minutes to } 4 \\
\text { hours }\end{array}$ & $303-373$ & $62,72,73$ \\
\hline 3. & Sonochemical & $\begin{array}{c}\text { Ultrasonic } \\
\text { Radiation }\end{array}$ & $\begin{array}{c}30-180 \\
\text { minutes }\end{array}$ & $273-313$ & $62,72,73$ \\
\hline 4. & Slow Evaporation & $\begin{array}{c}\text { No External } \\
\text { Energy }\end{array}$ & $\begin{array}{c}7 \text { days to } 7 \\
\text { months }\end{array}$ & 298 & $62,72,73$ \\
\hline 5. & Mechanochemical & $\begin{array}{c}\text { Mechanical } \\
\text { Energy }\end{array}$ & $\begin{array}{c}30 \text { minutes to } \\
2 \text { hours }\end{array}$ & 298 & $62,72,73$ \\
\hline 6. & Electrochemical & $\begin{array}{c}\text { Electrical Energy } \\
10 \text { to 30 } \\
\text { minutes }\end{array}$ & $273-303$ & $62,72,73$ \\
\hline
\end{tabular}

Several methods such as slow evaporation method, solvothermal method, microwaveassisted synthesis, electrochemical synthesis, mechanochemical synthesis, and sonochemical synthesis have been applied for the synthesis of MOF [62]. All these synthesis methods require different conditions that are represented in Table 1. However these techniques have several limitations as they require instrumentations that are highly expensive and they are energy as well as time consuming and also require high temperatures. Therefore it becomes necessary to develop a simple, ecologically-friendly preparation method in order to meet the industrial production needs. And hence the reflux method act as one of the promising method for the large-scale synthesis as it requires 
simple instrumentation and the reaction occurs at atmospheric pressure. Some method involve mixing of MOF precursors with composing material that is presynthesized and then further procedure of synthesis can be carried out. One of the widely reported such type of material is graphite oxide/MOF (GO/MOF) due to its various applications [7578].

\section{Sensors based on MOF for environmental applications}

The increase in pollution due to variety of pollutants introduced into the environment lead to the development of sensors that can detect these pollutants. Heavy metals, anions, organics, inorganics, bacteria and antibiotics in water are highly harmful to both the human health and the ecological environment. Therefore the demand for development of sensitive and reliable sensors in order to determine the water contamination has increased. The chemical detections in an aqueous solution are widely utilizing MOFs due to their unique characters for selective detection and determination of analytes. They can show reversible adsorption and release of target molecules due to their large surface area as well as porosity. These unique properties of MOF and their composites help to develop sensors based on MOF that can utilize luminescent, colorimetric or electrochemical signals. The sensing performances of these sensor have shown promising results in the determination of several water pollutants, although these sensors are based on different sensing mechanisms.

\section{Electrochemical sensor based on MOF for environmental applications}

MOF based electrochemical sensors are widely involved in most areas of technological society such as medicine, public health, energy control and environmental quality monitoring. In environmental pollution monitoring MOF based electrochemical sensors are used in three main areas such as toxics in water, organics and gases including volatile organics (VOCs). One of the major reasons for environmental pollution is the chemical route of pollution. Chemicals are released into the environment and they disturb the balance of our ecosystem, affecting our health, polluting the air we breathe and also contaminating our food. Therefore, the electrochemical sensors based on MOF are developed that are based on the measurement of electric current, electric potential, or any other electrical signal [79, 80]. MOFs are showing wide potential to be used as the surface for sensing based on electrochemical signals because they show high surface area as well as volume of the pore. Catalytic activity is also high as they are showing good absorbability [81, 82]. Several MOF based electrochemical sensors are developed that are used in the determination of several contaminants present in the environment (Table 2). 


\subsection{Heavy metal ion detection}

Due to the rapid industrialization, heavy metal ion pollution is becoming a challenging issue as it effects the survival of living organism on our earth. Heavy metals are defined as metals with atomic weight between 63.5 and $200.6 \mathrm{~g} \mathrm{~mol}^{-1}$ and a specific gravity greater than $5 \mathrm{~g} \mathrm{~cm}^{-3}$ [83-86]. The major sources through which heavy metal ion pollution created are industrial wastewater, lead-acid batteries, fertilizers, smelting, tanneries, metal plating, etc. [87]. They can easily accumulate in foods such as aquatic products, land animals and vegetables as they are non biodegradable. These heavy metals can enter plant, animal and human tissues through diet, air inhalation, and also can enter through manual handling. Through the uptake of water heavy metals enter the plants; through plants they can enter the animal bodies that are feeding on plants [88-92]. In this way plant and animal based foods are among the largest sources of heavy metal in humans $[84,85$,$] . These heavy metals can bind our cellular components such as protein, nucleic$ acid, enzymes, etc. and can disturb their functioning.

For metal ion analysis several analytical techniques including inductively coupled plasma mass spectrometry, atomic absorption spectrometry, atomic emission spectrometry and anodic stripping voltammetry have been used [93-96]. One of the highly sensitive and selective techniques for trace heavy metal detection is electrochemical stripping voltammetric technique that involves advanced electrochemical measurement of analytes accumulated in an effective preconcentration step [97-99]. Most of the electrode materials show a number of limitations. Among these several limitations the major ones are low surface areas, limited possibility for surface modification at which the process of electron transfer takes place and lack in structural design. Behind these limitations, the electrode materials behave as the heart of electrochemical sensors. Therefore, the researchers are fully devoted for designing advanced electrode materials having well defined physical and chemical properties that will improve the electrochemical performances. In the last few decades one of the important advances in materials science has occurred due to the development in the design of metal-organic frameworks (MOFs) with high surface areas, chemical tunability and uniform pores [100, 101]. MOFs with these characteristics act as a unique materials with potential for diverse applications [102105]. MOFs show multiple issues of poor conductivity and instability in aqueous solution and due to this the use of MOFs as novel electrode materials have been under explored. Coupling of MOFs with carbon materials such as carbon spheres [106], metal nanoparticles (Au [107], Pt [108]) and macroporous carbon [109] showed an effective approach in order to improve the mechanical strength and conductive performance of the MOFs and have shown some promise in area of electrochemical biosensor. But as the 
synthesis processes of these materials are not very easy their wider practical applications were greatly inhibited in the electrochemical field.

\subsubsection{Detection of lead ion $\left(\mathrm{Pb}^{2+}\right)$}

One of the most commonly found heavy metal ions in aquatic systems is lead ion $\left(\mathrm{Pb}^{2+}\right)$ and it is also considered as one of the most toxic heavy metal also. High intake of lead ions and its exposure for longer duration can cause memory loss, irritability, anemia, reproductive, cardio-vascular, neurological, developmental and several other disorders. Thus it becomes necessary to monitor even trace amount of $\mathrm{Pb}^{2+}$ in the water environment as well as in food industry regarding public health [110]. Several conventional techniques such as atomic absorption spectroscopy (AAS), atomic fluorescence spectrometry (AFS) and inductively coupled plasma mass spectrometry (ICP-MS) are widely used for determination of $\mathrm{Pb}^{2+}$. Although these methods are sufficiently sensitive but they are also highly complicated. Thus it becomes an important task to develop a rapid, highly sensitive and convenient method for $\mathrm{Pb}^{2+}$ ion analysis and for this MOFs based electrochemical sensors show many advantages over other electrochemical sensors.

For the detection of $\mathrm{Pb}^{2+}$, the He group [111] developed a strategy using Pd-Pt alloymodified Fe-MOFs (Fe-MOFs/PdPt NPs) along with hairpin DNA that was immobilized on the surface as a signal tag. For the immobilization of more DNAzyme they used streptavidin modified reduced graphene oxide-tetraethylene pentamine-gold nanoparticles (rGO-TEPA-Au) as a sensor platform. The new single-DNA can be produced by cleaving the ribonucleotide at its specific site by using DNAzyme in the presence of $\mathrm{Pb}^{2+}$. Then the hybrid strand of hairpin DNA is matched with its complement to the single- DNA and was employed for modifying the Fe-MOFs/PdPt NPs bioconjugates for amplifying the signal. The Fe-MOFs/PdPt NPs can catalyze the production of electrochemical signal from the hydrogen peroxide $\left(\mathrm{H}_{2} \mathrm{O}_{2}\right)$ which can be recorded by chronoamperometry. In this way by using this method $\mathrm{Pb}^{2+}$ can be determined selectively in the presence of other metal ions and this selectivity is due to $\mathrm{Pb}^{2+}$ dependent DNAzyme. The developed biosensor corresponds to a low detection limit of $2 \mathrm{pM}(\mathrm{S} / \mathrm{N}=3)$ and also exhibited a good linear relationship ranging from 0.005 to $1000 \mathrm{nmol} \mathrm{L}^{-1}$ for the sensing of $\mathrm{Pb}^{2+}$ ion. High sensitivity and selectivity is shown by this newly designed ultrasensitive biosensor based on $\mathrm{Pb}^{2+}$ dependent DNAzyme.

Based on MOFs another electrochemical sensor was also developed for the sensing of $\mathrm{Pb}^{2+}$ ion and it was designed by Guo et al. [112] They developed a novel metal-organic framework (MOF) material that was flake-like $\mathrm{NH}_{2}-\mathrm{MIL}-53(\mathrm{Cr})$, by using a simple reflux method. This prepared MOF can behave as an effective material for electrochemical 
determination of $\mathrm{Pb}^{2+}$ ion in aqueous sample even at the microgram levels. Square wave anodic stripping voltammetry is used as the detection technique. The surface of glassy carbon electrode (GCE) was modified by $\mathrm{NH}_{2}$-MIL-53(Cr) that showed an excellent stability and selectivity for the determination of $\mathrm{Pb}^{2+}$ ion. This modified GCE is used for the study of electrochemical properties and applications. Some operational parameters such as deposition time, deposition potential and $\mathrm{pH}$ were optimized to detect even trace amount of metal ions. In this way this method developed a new way for heavy metal detection using MOF materials. Excellent electronic response is obtained for $\mathrm{Pb}^{2+}$ ion by using this sensor. As the concentration of $\mathrm{Pb}^{2+}$ is increased under optimal conditions in the range of $0.4-80 \mu \mathrm{M}$ the oxidation current is increased linearly. It also showed a very good detection limit of $30.5 \mathrm{nM}$.

\subsubsection{Detection of copper ion $\left(\mathrm{Cu}^{2+}\right)$}

The biological availability of copper ions in water is more than in food. Copper ions are also highly toxic and can cause several disorders in living organisms. Several methods have been designed for the determination of copper ions however the MOF based electrochemical sensor play a very crucial role in the determination of lead ion. These MOF based electrochemical sensor show high accuracy, sensitivity and precision. Therefore the way used in determination of lead ion $\left(\mathrm{Pb}^{2+}\right)$ is also used for the electrochemical measurements of copper (II) in the presence of MOF-based electrochemical sensor. During the measurement of copper (II), an anionic MOF i.e. AuNPs/ $\mathrm{Me}_{2} \mathrm{NH}_{2} @ M O F-1 / G C E$ was dipped in solution containing copper (II) so that preconcentration of copper can takes place. The square wave anodic stripping voltammetry (SW ASV) is the technique used for the electrochemical measurement of copper ion $[113,114]$.

\subsection{Sensing of inorganic ions}

Among several inorganic pollutants present in water, most of them are not very toxic but due to their extensive use they are still dangerous for our environment. These inorganic pollutants may include nitrates and phosphates that are extensively present in fertilizers and hence they can reach to the water body very easily. Besides these inorganic pollutants several other pollutants are also present in water and they are dangerous both for human being and their environment. Thus it becomes necessary to monitor these inorganic pollutants. Several techniques have been employed for this purpose but most of them show several limitations of poor selectivity, sensitivity and detection limit. Therefore the development of MOF based electrochemical sensor have tendency to remove these limitations. Several inorganic pollutants can be detected by using MOF based electrochemical sensor. 


\subsubsection{Detection of Nitrite ion $\left(\mathrm{NO}_{2}{ }^{-}\right)$}

One of the important contaminant in water is nitrite ion. Nitrite ions have been extensively used by human beings for several purposes such as in drinking water, vegetables, as fertilizing agents and as food preservatives. Nitrites are highly toxic to both humans and animals, especially infants. Nitrite is a nutrient which is essential for plant growth and it can enter the body of living organisms as nitrate which can be easily converted to nitrite through various mechanisms. It disrupts the various biochemical processes of living organisms by affecting the ability of hemoglobin in oxygen delivering process in the bloodstream. If an infant is exposed with nitrite in water or formula mixed with water that is contaminated with nitrate then the disorder known as blue baby syndrome (methemoglobinemia) may be develop in the body of infant that behave as a life threatening disorder. Several other disorders such as hypertension, stomach cancer can also occur due to the adverse effect of nitrite ion. Therefore it became an important requirement to develop nitrite sensors for regular monitoring of the harmful nitrite ions with accuracy. Although number of analytical techniques has been already developed for the determination of toxic nitrites but most of these techniques have no reliability because these techniques are very tedious and time consuming. Electrochemical sensors however provide several advantages such as simple handling, safety, reliability, stability, rapidity, selectivity and sensitivity and therefore due to these features they have gained significant research interest. But the traditional electrodes cannot be used for accurate and rapid sensing of nitrite ion due to very high oxidation potential of nitrite. Recently MOF based electrochemical sensors have been developed that serve as a better tool for nitrite ion determination than the other developed nitrite sensors.

A MOF/rGO hybrid electrode was developed by Mobin group [115] for the electrocatalytic oxidative determination of nitrite. In this study, by using simple ultrasonication method Cu-MOFs were stacked with rGO. In order to achieve better electrocatalytic performance for nitrite ion determination the GCE is modified with $\mathrm{Cu}-$ $\mathrm{MOF} / \mathrm{rGO}$ composites because GCE modified with Cu-MOF/rGO composites exhibited better LOD of $0.033 \mathrm{mM}$ than those of an MOF electrode or bare electrode. The sensing performance of the modified GCE is better due to the increase in conductivity of MOF with rGO. In addition to this improvement in performance it also showed good selectivity for the nitrite ions in the presence of some common salts such as $\mathrm{NaClO}_{4}, \mathrm{CaCl}_{2}, \mathrm{MgSO}_{4}$, $\mathrm{KCl}, \mathrm{CH}_{3} \mathrm{COONa}$ and $\mathrm{KNO}_{3}$. The activity of this sensor was also checked for pond water spiked with nitrite ion and the recoveries were observed up to 100-120\%. 


\subsection{Sensing of organic compounds}

Like inorganic ions and heavy metals, there are also large numbers of organic molecules that can act as pollutants in water environment. Generally these organic moieties are highly toxic and show lower degradability and hence they can cause very bad effects to our environment. Therefore it becomes imperative to perform some studies so that it becomes easy to monitor their effect on the environment and living organisms. Several researchers have tried to study their origin, effect on the environment and their control. One such study show that some dihydroxybenzene isomers (DBIs) of phenolic compounds such as catechol (CT), resorcinol (RS), and hydroquinone (HQ) can act as water pollutants [116]. They are toxic and showing lower degradability and hence they are hazardous both for living organisms and their environment. So it becomes demanding to develop some rapid and simple analytical technology for determination of these organic components present as pollutants in nature. Today several analytical methods such as fluorescence, chemiluminiscence, high performance liquid chromatography, spectrophotometry, mass spectrometry, capillary electrochromatography and electrochemical methods have been employed in quantitative determination of DBIs. Most of these techniques are not efficient in sensitive and selective determination. However, due to several advantages such as fast response, low cost, high sensitivity, excellent selectivity and lower detection limit, the electrochemical methods are used widely in this field. But the simultaneous determination of these three isomers that are $\mathrm{CT}$, RS and HQ are not so easy because these isomers have similar stereochemical structure and having close redox potentials on common electrode. In order to overcome these limitations in simultaneous determination of these DBIs, some functional materials such as carbon nanotubes, metal sulfides, quantum dots, graphene have been utilized as electrochemical sensing materials. But we do not use these materials in order to solve the problems because these materials involve very complicated synthesis process, high toxicity and/or poor analytical response. Therefore to develop a rapid and convenient sensing platform for simultaneous determination of DBIs is still a challenge. However the development of MOF-based electrochemical sensor has shown very promising result in the determination of these organic moieties [117].

One chitosan (CS) coated electrode along with the doping of GO was developed for the detection of these DBIs [117]. This method involves the electrochemical reduction of GO to rGO in the CS/GO composite by using some electrorduction method. This rGO was used as supporting carrier for the grafting of electroactive MOF i.e. $\mathrm{Cu}_{3}(\mathrm{BTC})_{2}$ and it also showed high electrical conductivity. Electrochemical measurement shows good selectivity because the reduction peaks of RS, CT, and HQ are well separated from each other. The current response of the CS/rGO matrix is improved because it shows high 
conductivity and hence good LODs of $0.44,0.41$, and $0.33 \mu \mathrm{M}$ can be achieved for HQ, CT, and RS respectively [110, 117]. This MOF based electrochemical sensor has been successfully applied for the determination of DBIs in real water sample with high accuracy. That's why the MOFs based electrochemical sensors are widely used in the organic compound sensing.

Another electrochemical sensor based on MOFs was designed by the Wang group [118] for the detection of DBIs. Here they synthesized magnetic Ni@graphene composites having core-shell structure, C-SNi@G through thermal annealing of Ni-BTC MOF. By using bare electrode HQ and CT cannot be differentiated because the oxidation peaks of HQ and CT overlap each other. Hence during the cyclic voltammetric studies only one oxidation peak was observed by using bare electrode. However by using the CSNi@G/MGCE as an electrode, two well separated peaks were observed at $0.085 \mathrm{~V}$ for HQ and $0.190 \mathrm{~V}$ for CT vs Ag/AgCl [110,118].

A highly sensitive electrochemical sensor was developed by the Liu group [119] for the simultaneous determination of HQ and CT in water sample and it was based on coppercentered MOF-graphene composites [Cu-MOF-GN, Cu-MOF: $\mathrm{Cu}_{3}(\mathrm{BTC})_{2}$ ]. However excellent elecrocatalytic activity and high selectivity can be observed for HQ and CT when Cu-MOF-GN electrode was used under optimized conditions. This MOF based electrode show very low detection limit $0.59 \mathrm{M}$ for HQ and $0.331 \mathrm{M}$ for CT, respectively [110,119].

Besides these DBIs, some other phenolic compounds are also harmful to humans and our environment. These include chlorinated phenol contaminants such as 2,4-dichlorophenol (2,4-DCP) that are present in water and they may also enter the human body through the food chain. This 2,4-DCP can cause harm for human health even when present in very low concentration [120]. 2,4-DCP can be selectively determined by using MOF based electrochemical sensor i.e. 1,3,5-benzenetricarboxylic acid copper. This developed sensor for 2, 4-DCP is not only showing high selectivity but it also show broad range for sensing i.e. from 0.04 to $1.01 \mathrm{M}$ and very low LOD of $9 \mathrm{nM}$. This copper based MOF sensor show several advantages: (i) It has large surface area, (ii) It shows high adsorption capacity and (iii) It has also good electron transfer efficiency. These advantages help in enhancing the performance of electrochemical sensor. This developed sensor is also applied for the determination of 2, 4-DCP present in raw water samples [121]. 
Table 2 MOF-based electrochemical sensors for determination of contaminants present in water.

\begin{tabular}{|c|c|c|c|c|c|}
\hline S.No. & $\begin{array}{c}\text { MOF-based } \\
\text { sensing material }\end{array}$ & $\begin{array}{l}\text { Analytes to be } \\
\text { detected }\end{array}$ & LOD & $\begin{array}{l}\text { Sample } \\
\text { used for } \\
\text { testing }\end{array}$ & References \\
\hline 1. & $\mathrm{Zn}_{4} \mathrm{O}(\mathrm{BDC})_{3}$ & $\mathrm{~Pb}^{2+}$ & $4.9 \mathrm{nM}$ & Real water & 122 \\
\hline 2. & Fe-MOFs/PdPt NPs & $\mathrm{Pb}^{2+}$ & $2 \mathrm{pM}$ & $\begin{array}{c}\text { Reservoir } \\
\text { water, well } \\
\text { water, tap } \\
\text { water } \\
\end{array}$ & 111 \\
\hline 3. & $\mathrm{NH}_{2}$-MIL-53(Cr) & $\mathrm{Pb}^{2+}$ & $30.5 \mathrm{nM}$ & & 112 \\
\hline 4. & $\mathrm{Me}_{2} \mathrm{NH}_{2} @ \mathrm{MOF}-1$ & $\mathrm{Cu}^{2+}$ & $1 \mathrm{pM}$ & river water & 113,114 \\
\hline 5. & Cu-MOF/rGO & $\mathrm{NO}^{2-}$ & $33 \mathrm{nM}$ & pond water & 117 \\
\hline 6. & UiO-66-NH & $\mathrm{NO}^{2-}$ & $0.01 \mu \mathrm{M}$ & & 123 \\
\hline \multirow[t]{4}{*}{7.} & \multirow[t]{4}{*}{$\mathrm{Cu}_{3}(\mathrm{BTC})_{2}$} & Hydroquinone & $0.44 \mu \mathrm{M}$ & & 110 \\
\hline & & Catechol & $0.41 \mu \mathrm{M}$ & & 110 \\
\hline & & Resorcinol & $0.33 \mu \mathrm{M}$ & & 110 \\
\hline & & 2,4-dichlorophenol & $9 \mathrm{nM}$ & $\begin{array}{l}\text { reservoir } \\
\text { raw water }\end{array}$ & 121 \\
\hline \multirow[t]{2}{*}{8.} & \multirow[t]{2}{*}{ Cu-MOF-199/SWCTs } & Hydroquinone & $0.08 \mu \mathrm{M}$ & river water & 124 \\
\hline & & Catechol & $1 \mu \mathrm{M}$ & river water & 124 \\
\hline
\end{tabular}

\section{Conclusion}

Environmental pollutions are increasing day-by-day, due to several inorganic and organic pollutant thus it becomes demanding for the development of sensors that can detect these pollutants and helps in their removal. Several chemical, fluorescence, UV, electrochemical sensors are developed for the determination of these pollutants even when present at low concentration. Among these sensors, the electrochemical sensors developed show very promising result in the determination of these inorganic or organic pollutants. But the conventional electrochemical sensors developed do not show very low detection limit. They also do not have high selectivity, specificity and accuracy. Therefore Metal-organic frameworks (MOFs) are used in designing electrochemical sensors that are showing high selectivity, specificity and accuracy and also they have a lower limit of detection. These MOFs used in electrochemical sensing are prepared by chelating metal ions with organic moieties. MOFs have large surface area; they are rich in porosity and active sites; also the pore sizes are highly flexible. Hence due to these behaviors they are used in the construction of electrochemical sensor. Several MOFs 
based electrochemical sensors are developed such as $\mathrm{NH}_{2}-\mathrm{MIL}-53(\mathrm{Cr})$ for the determination of $\mathrm{Pb}^{2+}$ ion, MOF/rGO hybrid electrode for the determination of nitrite ions, $\mathrm{Cu}-\mathrm{MOF}-\mathrm{GN}$, Cu-MOF: $\mathrm{Cu}_{3}(\mathrm{BTC})_{2}$ are used for sensing catechol and hydroquinone. Generally MOFs are widely used for removal of pollutants through adsorption and only few MOF based electrochemical sensors are available for the determination of inorganic as well as organic pollutants. However, due to its wide potential in the field of electrochemistry, materials based on MOF will show lot of promise for the detection of different pollutants. Therefore, research is fast in progress to develop MOF based electrochemical sensor in order to overcome the limitations of other electrochemical sensors.

\section{References}

[1] F.Y. Yi, R. Zhang, H. Wang, L.F. Chen, L. Han, H. L. Jiang, and Q. X, MetalOrganic Frameworks and Their Composites: Synthesis and Electrochemical Applications, Small Methods 1 (2017) 1700187. https://doi.org/10.1002/smtd.201700187

[2] O. M. Yaghi, G. M. Li, H. L. Li, Selective binding and removal of guests in a microporous metal-organic framework, Nature 378 (1995) 703. https://doi.org/10.1038/378703a0

[3] B. F. Hoskins, R. Robson, Infinite polymeric frameworks consisting of three dimensionally linked rod-like segments, J. Am. Chem. Soc. 111(1989) 5962. https://doi.org/10.1021/ja00197a079

[4] B. F. Hoskins, R. Robson, Design and construction of a new class of scaffolding-like materials comprising infinite polymeric frameworks of 3D-linked molecular rods. A reappraisal of the zinc cyanide and cadmium cyanide structures and the synthesis and structure of the diamond-related frameworks $\left[\mathrm{N}\left(\mathrm{CH}_{3}\right)_{4}\right]\left[\mathrm{Cu}(\mathrm{I}) \mathrm{Zn}(\mathrm{II})(\mathrm{CN})_{4}\right]$ and $\mathrm{Cu}(\mathrm{I})[4,4$ ',4",4"'-tetracyanotetraphenylmethane $] \mathrm{BF}_{4} \cdot \mathrm{xC}_{6} \mathrm{H}_{5} \mathrm{NO}_{2}$, J. Am. Chem. Soc. 112 (1990) 1546. https://doi.org/10.1021/ja00160a038

[5] D. Venkataraman, G. B. Gardner, S. Lee, J. S. Moore, Zeolite-like Behavior of a Coordination Network, J. Am. Chem. Soc. 117 (1995) 11600. https://doi.org/10.1021/ja00151a034

[6] G. B. Gardner, D. Venkataraman, J. S. Moore, S. Lee, Spontaneous assembly of a hinged coordination network, Nature 374 (1995) 792. https://doi.org/10.1038/374792a0

[7] G. Férey, Hybrid porous solids: past, present, future, Chem. Soc. Rev. 37 (2008) 191. https://doi.org/10.1039/b618320b 
[8] S. Horike, S. Shimomura, S. Kitagawa, Soft porous crystals, Nat. Chem. 1(2009) 695.

[9] H. Furukawa, K. E. Cordova, M. O’Keeffe, O. M. Yaghi, The Chemistry and Applications of Metal-Organic Frameworks, Science341 (2013) 974.

[10] J. M. Yoon, R. Srirambalaji, K. Kim, Homochiral, Metal-Organic Frameworks for Asymmetric Heterogeneous Catalysis, Chem. Rev. 112 (2012) 1196. https://doi.org/10.1021/cr2003147

[11] J. Liu, L. Chen, H. Cui, J. Zhang, L. Zhang, C.-Y.Su, Applications of metal-organic frameworks in heterogeneous supramolecular catalysis, Chem. Soc.Rev. 43 (2014) 6011. https://doi.org/10.1039/c4cs00094c

[12] G. Huang, Y.-Z.Chen, H.-L.Jiang, Metal-organic frameworks for Catalysis, Acta. Chim. Sin. 74 ( 2016) 113.

[13] Y.-Z. Chen, Z. U. Wang, H. Wang, J. Lu, S.-H.Yu, H.-L. Jiang, Singlet OxygenEngaged Selective Photo-Oxidation over Pt Nanocrystals/Porphyrinic MOF: The Roles of Photothermal Effect and Pt Electronic State, J. Am. Chem. Soc. 139(2017) 2035. https://doi.org/10.1021/jacs.6b12074

[14] S. Ou, C.-D.Wu, Rational construction of metal-organic frameworks for heterogeneous catalysis, Inorg. Chem. Front. 1 (2014) 721. https://doi.org/10.1039/c4qi00111g

[15] L. Zeng, X. Guo, C. He, C. Duan, Metal-Organic Frameworks: Versatile Materials for Heterogeneous Photocatalysis, ACS Catal. 6 (2016) 7935. https://doi.org/10.1021/acscatal.6b02228

[16] A. Aijaz, A. Karkamkar, Y. J. Choi, N. Tsumori, E. Rönnebro,T. Autrey, H. Shioyama, Q. Xu, Immobilizing Highly Catalytically Active Pt Nanoparticles inside the Pores of Metal-Organic Framework: A Double Solvents Approach, J. Am. Chem. Soc. 134 (2012) 13926. https://doi.org/10.1021/ja3043905

[17] R. Q. Zou, H. Sakurai, S. Han, R. Q. Zhong, Q. Xu, Probing the Lewis Acid Sites and $\mathrm{CO}$ Catalytic Oxidation Activity of the Porous Metal-Organic Polymer [ $\mathrm{Cu}(5$ methylisophthalate)], J. Am. Chem. Soc. 129 (2007) 8402. https://doi.org/10.1021/ja071662s

[18] J. Y. Lee, O. K. Farha, J. Roberts, K. A. Scheidt, S. T. Nguyen, J. T. Hupp, Metalorganic framework materials as catalysts, Chem. Soc. Rev 38( 2009) 1450. https://doi.org/10.1039/b807080f

[19] A. Corma, H. García, F. X. Llabrés-Xamena, Engineering Metal Organic Frameworks for Heterogeneous Catalysis, Chem. Rev. 110 (2010) 4606. https://doi.org/10.1002/chin.201046237 
[20] J.-L. Wang, C. Wang, W. Lin, Metal-Organic Frameworks for Light Harvesting and Photocatalysis, ACS Catal. 2 (2012) 2630. https://doi.org/10.1021/cs3005874

[21] Q.-L. Zhu, Q. Xu, Immobilization of Ultrafine Metal Nanoparticles to High-SurfaceArea Materials and Their Catalytic Applications, Chem 1 (2016) 220. https://doi.org/10.1016/j.chempr.2016.07.005

[22] X. Gu, Z.-H. Lu, H.-L. Jiang, T. Akita, Q. Xu, Synergistic Catalysis of MetalOrganic Framework-Immobilized Au-Pd Nanoparticles in Dehydrogenation of Formic Acid for Chemical Hydrogen Storage, J. Am. Chem. Soc. 133 (2011) 11822. https://doi.org/10.1021/ja200122f

[23] P.-Z. Li, K. Aranishi, Q. Xu, ZIF-8 immobilized nickel nanoparticles: highly effective catalysts for hydrogen generation from hydrolysis of ammonia borane, Chem. Commun. 48 (2012) 3173. https://doi.org/10.1039/c2cc17302f

[24] Q.-L. Zhu, J. Li, Q. Xu, Immobilizing Metal Nanoparticles to Metal-Organic Frameworks with Size and Location Control for Optimizing Catalytic Performance, J. Am. Chem. Soc. 135 (2013) 10210. https://doi.org/10.1021/ja403330m

[25] P. Pachfule, X. Yang, Q.-L. Zhu, N. Tsumori, T. Uchidaa, Q. Xu,From Ru nanoparticle-encapsulated metal-organic frameworks to highly catalytically active Cu/Ru nanoparticle-embedded porous carbon, J. Mater. Chem. A. 5 (2017) 4835. https://doi.org/10.1039/c6ta10748f

[26] J.-P. Zhang, X.-M. Chen, Exceptional Framework Flexibility and Sorption Behavior of a Multifunctional Porous Cuprous Triazolate Framework, J. Am. Chem. Soc. 130 (2008) 6010. https://doi.org/10.1021/ja800550a

[27] J. R. Li, R. J. Kuppler, H. C. Zhou, Selective gas adsorption and separation in metalorganic fameworks Chem. Soc. Rev. 38 (2009) 1477. https://doi.org/10.1039/b802426j

[28] M. P. Suh, H. J. Park, T. K. Prasad, D. W. Lim, Hydrogen Storage in Metal-Organic Frameworks, Chem. Rev. 112(2012) 782.

[29] H. H. Wu, Q. H. Gong, D. H. Olson, J. Li, Commensurate Adsorption of Hydrocarbons and Alcohols in Microporous Metal Organic Frameworks, Chem. Rev. 112 (2012) 836. https://doi.org/10.1021/cr200216x

[30] S. H. Yang, X. Lin, W. Lewis, M. Suyetin, E. Bichoutskaia,J. E. Parker, C. C. Tang, D. R. Allan, P. J. Rizkallah, P. Hubberstey, N. R. Champness, K. M. Thomas, A. J. Blake, M. Schröder, A partially interpenetrated metal-organic framework for selective hysteretic sorption of carbon dioxide, Nat. Mater. 11 (2012) 710. https://doi.org/10.1038/nmat3343

[31] P. Nugent, Y. Belmabkhout, S. D. Burd, A. J. Cairns, R. Luebke,K. Forrest, T. Pham, S. Ma, B. Space, L. Wojtas, M. Eddaoudi,M. J. Zaworotko, Porous materials 
with optimal adsorption thermodynamics and kinetics for $\mathrm{CO}_{2}$ separation, Nature 495 (2013) 80. https://doi.org/10.1038/nature11893

[32] Y. Peng, V. Krungleviciute, I. Eryazici, J. T. Hupp, O. K. Farha,T. Yildirim, Methane Storage in Metal-Organic Frameworks: Current Records, Surprise Findings, and Challenges, J. Am. Chem. Soc. 135 ( 2013) 11887.

https://doi.org/10.1021/ja4045289

[33] K. Sumida, D. L. Rogow, J. A. Mason, T. M. McDonald, E. D. Bloch, Z. R. Herm, T. H. Bae, J. R. Long, Carbon Dioxide Capture in Metal-Organic Frameworks, Chem. Rev. 112 (2012) 724. https://doi.org/10.1021/cr2003272

[34] Y. He, W. Zhou, G. Qian, B. Chen, Methane storage in metal-organic frameworks, Chem. Soc. Rev. 43(2014) 5657. https://doi.org/10.1039/c4cs00032c

[35] J. R. Li, J. Sculley, H. C. Zhou, Metal-Organic Frameworks for Separations, Chem. Rev. 112(2012)869. https://doi.org/10.1021/cr200190s

[36] B. V. de Voorde, B. Bueken, J. Denayer, D. De Vos, Adsorptive separation on metal organic frameworks in the liquid phase, Chem. Soc.Rev.43 ( 2014) 5766. https://doi.org/10.1039/c4cs00006d

[37] S. Qiu, M. Xue, G. Zhu, Metal-organic framework membranes: from synthesis to separation application, Chem. Soc. Rev.43(2014) 6116. https://doi.org/10.1039/c4cs00159a

[38] Q.-L. Zhu, Q. Xu, Liquid organic and inorganic chemical hydrides for high-capacity hydrogen storage, Energy Environ. Sci. 8 (2015) 478.

https://doi.org/10.1039/c4ee03690e

[39] F.-Y. Yi, D. Chen, M.-K.Wu, L. Han, H.-L. Jiang, Chemical Sensors Based on Metal-Organic Frameworks, Chem Plus Chem 81 (2016) 675.

[40] B. L. Chen, S. C. Xiang, G. D. Qian, Metal-organic frameworks with functional pores for recognition of small molecules, Acc. Chem. Res. 43 (2010) 1115. https://doi.org/10.1021/ar100023y

[41] L. E. Kreno, K. Leong, O. K. Farha, M. Allendorf, R. P. V. Duyne,J. T. Hupp, Metal-Organic Framework Materials as Chemical Sensors, Chem. Rev. 112 (2012) 1105. https://doi.org/10.1021/cr200324t

[42] Z. Hu, B. J. Deibert, J. Li, Luminescent metal-organic frameworks for chemical sensing and explosive detection, Chem. Soc. Rev. 43 (2014) 5815. https://doi.org/10.1039/c4cs00010b

[43] P. Horcajada, R. Gref, T. Baati, P. K. Allan, G. Maurin, P. Couvreur,G. Férey, R. E. Morris, C. Serre, Metal-Organic Frameworks in Biomedicine, Chem. Rev. 112 (2012) 1232. https://doi.org/10.1021/cr200256v 
[44] C. He, D. Liu, W. Lin, Nanomedicine Applications of Hybrid Nanomaterials Built from Metal-Ligand Coordination Bonds: Nanoscale Metal-Organic Frameworks and Nanoscale Coordination Polymers, Chem. Rev. 115 (2015) 11079. https://doi.org/10.1021/acs.chemrev.5b00125

[45] Y. Cui, Y. Yue, G. Qian, B. Chen, Luminescent Functional Metal-Organic Frameworks, Chem. Rev. 112 (2012) 1126. https://doi.org/10.1021/cr200101d [46] P. Cheng, Lanthanide Metal-Organic Frameworks, Structure and Bonding Series, Springer, New York, USA (2015)

[47] J Lei, R. Qian, P. Ling, L. Cui, H.Ju, Design and sensing applications of metalorganic framework composites, Trends in Analytical Chemistry, 58 (2014) 71-78. https://doi.org/10.1016/j.trac.2014.02.012

[48] L.E. Kreno, K. Leong, O.K. Farha, M. Allendorf, R.P. Van Duyne, J.T. Hupp, Metal organic framework materials as chemical sensors, Chem. Rev. 112 (2012)1105-1125. https://doi.org/10.1021/cr200324t

[49] F. Sun, Z. Yin, Q.Q. Wang, D. Sun, M.H. Zeng, M. Kurmoo, Tandem postsynthetic modification of a metal-organic framework by thermal elimination and subsequent bromination: effects on absorption properties and photoluminescence, Angew. Chem. Int. Ed. 52 (2013) 4538-4543. https://doi.org/10.1002/anie.201300821

[50] X.Q. Wu, J.G. Ma, H. Li, D.M. Chen, W. Gu, G.M. Yang, P. Cheng, Metal-organic framework biosensor with high stability and selectivity in a bio-mimic environment., Chem. Commun. 51(44) (2015)9161-9164. https://doi.org/10.1039/c5cc02113h

[51] D. Sheberla, L. Sun, M.A. Blood-Forsythe, S. Er, C.R. Wade,C.K. Brozek, A. Aspuru-Guzik, M. Dinca, High electrical conductivity in Ni(3)(2,3,6,7,10,11hexaiminotriphenylene)(2), a semiconducting metal-organic graphene analogue, J. Am. Chem. Soc. 136(25),(2014) 8859-8862. https://doi.org/10.1021/ja502765n

[52] M.G. Campbell, D. Sheberla, S.F. Liu, T.M. Swager, M. Dinca, $\mathrm{Cu}(3)$ (hexaiminotriphenylene)(2): an electrically conductive 2Dmetal-organic framework for chemiresistive sensing, Angew. Chem. Int. Ed. 54(14) (2015) 43494352. https://doi.org/10.1002/anie.201411854

[53] X. Wang, Q.X. Wang, Q.H. Wang, F. Gao, Y.Z. Yang,H.X. Guo, Highly dispersible and stable copper terephthalate metal-organic framework-graphene oxide nanocomposite for an electrochemical sensing application, ACS Appl. Mater.123Nano-Micro Lett. (2018) 10:64 Page 17 of 19 64Interfaces 6(14), 1157311580 (2014). https://doi.org/10.1021/am5019918 
[54] Z.D. Xu, L.Z. Yang, C.L. Xu, Pt@UiO-66 heterostructures for highly selective detection of hydrogen peroxide with an extended linear range, Anal. Chem. 87(6) (2015) 3438-3444. https://doi.org/10.1021/ac5047278

[55] P. Falcaro, R. Ricco, A. Yazdi, I. Imaz, S. Furukawa, D. Maspoch,R. Ameloot, J.D. Evans, C.J. Doonan, Application of metal and metal oxide nanoparticles@MOFs, Coord. Chem. Rev. 307 (2016) 237-254. https://doi.org/10.1002/chin.201609231

[56] J. Wang, J.T. Jiu, T. Araki, M. Nogi, T. Sugahara, S. Nagao, H.Koga, P. He, K. Suganuma, Silver nanowire electrodes: conductivity improvement without posttreatment and application in capacitive pressure sensors, Nano-Micro Lett. 7(1) (2015) 51-58. https://doi.org/10.1007/s40820-014-0018-0

[57] Z. Yang, Z.H. Li, M.H. Xu, Y.J. Ma, J. Zhang, Y.J. Su, F. Gao,H. Wei, L.Y. Zhang, Controllable synthesis of fluorescent carbon dots and their detection application as nanoprobes, Nano-Micro Lett. 5(4) (2013) 247-259. https://doi.org/10.1007/bf03353756

[58] I.Bontidean, C. Berggren, G. Johansson, E. Csoregi, B. Mattiasson, J.R. Lloyd, K.J Jakeman, N.L Brown, Detection of heavy metal ions at femtomolar levels using protein-based biosensors, Anal.Chem.70 (1998) 4162-4169. https://doi.org/10.1021/ac9803636

[59] D. Pan, Y. Wang, Z. Chen, T. Lou, W. Qin, Nanomaterial/Ionophore-Based Electrode for Anodic Stripping Voltammetric Determination of Lead: An Electrochemical Sensing Platform toward Heavy Metals, Anal. Chem. 81 ( 2009) 5088-5094. https://doi.org/10.1021/ac900417e

[60] C. Combellas, F. Kanoufi, J. Pinson, F.I. Podvorica, Sterically Hindered Diazonium Salts for the Grafting of a Monolayer on Metals, J.Am.Chem.Soc.130 (27) (2008) 8576-8577. https://doi.org/10.1021/ja8018912

[61] L. Fan, J. Chen, S. Zhu, M. Wang , G. Xu, Determination of Cd2+ and Pb2+ on glassy carbon electrode modified by electrochemical reduction of aromatic diazonium salts, Electrochem. Commun. 11 (2009) 1823- 1825. https://doi.org/10.1016/j.elecom.2009.07.026

[62] Z. Xie, W. Xu, X. Cui, and Y. Wang, Recent Progress in Metal-Organic Frameworks and Their Derived Nanostructures for Energy and Environmental Applications, Chem. Sus. Chem 10 (2017), 1645 - 1663. https://doi.org/10.1002/cssc.201601855

[63] M. Z. Jacobson, Review of solutions to global warming, air pollution, and energy security, Energy Environ. Sci. 2 (2009) 148-173. https://doi.org/10.1039/b809990c 
[64] V. Thavasi, G. Singh, S. Ramakrishna, Electrospun nanofibers in energy and environmental applications, Energy Environ. Sci. 1 (2008) 205 -221. https://doi.org/10.1039/b809074m

[65] Z. Q. Xie, X. D. Cui, W. W. Xu, Y. Wang, Metal-Organic framework Derived CoNi@CNTs embedded Carbon Nanocages for efficient dye-sensitized solar cells, Electrochim. Acta 229 (2017) 361-370. https://doi.org/10.1016/j.electacta.2017.01.145

[66] Z. L. Li, J. Chen, H. Y. Guo, X. Fan, Z. Wen, M. H. Yeh, C. W. Yu, X. Cao, Z. L. Wang, Triboelectrification-enabled self-powered detection and removal of heavy metal ions in wastewater, Adv. Mater. 28 (2016) 2983-2991. https://doi.org/10.1002/adma.201504356

[67] R. K. Sharma, M. Agrawal, Biological effects of heavy metals: an overview, J. Environ. Biol. 26 (2005) 301-313.

[68] S. H. Hsu, C. T. Li, H. T. Chien, R. R. Salunkhe, N. Suzuki, Y. Yamauchi,K. C. Ho, K. C. W. Wu, Platinum- free counter electode comprised of metal- organicframework(MOF)- derived cobalt sulfide nanoparticles for efficient dye-senitized solar cells (DSSCs) Sci. Rep.4 (2014) 6983. https://doi.org/10.1038/srep06983

[69] G. Aragay, J. Pons, A. Merkoci, Recent trends in macro-, micro-, and nanomaterialbased tools and strategies for heavy-metal detection, Chem. Rev. 111 (2011) 34333458. https://doi.org/10.1021/cr100383r

[70] E. Tahmasebi, M. Y. Masoomi, Y. Yamini, A. Morsali, Application of Mechano synthesized Azine-Decorated Zinc(II)Metal- Organic frameworks for highly efficient removal and extraction of some heavy-metal ions from aqueous samples: A comparative study, Inorg. Chem. 54 (2015) 425-433. https://doi.org/10.1021/ic5015384

[71] J.-N. Hao, B. Yan, A water-stable lanthanide- functionalized MOF as a highly selective and sensitive fluorescent probe for $\mathrm{Cd}^{2+}$, Chem. Commun. 51 (2015) 77377740. https://doi.org/10.1039/c5cc01430a

[72] N. Stock, S. Biswas, Synthesis of Metal-Organic Frameworks (MOFs): routes to various MOF Topologies, Morphologies, and composites, Chem. Rev. 112 (2012) 933-969. https://doi.org/10.1021/cr200304e

[73] C. Dey, T. Kundu, B. P. Biswal, A. Mallick and R. Banerjee,Crystalline metalorganic frameworks (MOFs): synthesis, structure and function, Acta. Cryst. B 70 (2014) 3-10. https://doi.org/10.1002/chin.201426232

[74] Sergio Carrasco , Metal-Organic Frameworks for the Development of Biosensors: A Current Overview, Biosensors 8 (2018), 92. https://doi.org/10.3390/bios8040092 
[75] C. Petit, et al. Langmuir, Toward Understanding reactive adsorption of ammonia on Cu-MOF/Graphite Oxide Nanocomposites 27 (2011) 13043-13051. https://doi.org/10.1021/la202924y

[76] C. Petit, B. Mendoza, T.J. Bandosz, Hydrogen sulfide adsorption on MOFs and MOF/ graphite oxide composites, ChemPhysChem 11 (2010) 3678-3684. https://doi.org/10.1002/cphc.201000689

[77] C. Petit, T.J. Bandosz, Synthesis, Characterization, and Ammonia Adsorption Properties of mesoporous metal-organic framework (MIL(Fe))-Graphite Oxide Composites: Exploring the limits of Materials Fabrication, Adv. Funct. Mater. 21 (2011) 2108-2117. https://doi.org/10.1002/adfm.201002517

[78] C. Petit, T.J. Bandosz, Exploring the coordination chemistry of MOF- graphite oxide composites and their applications as adsorbents, Dalton Trans. 41 (2012) 4027-4035. https://doi.org/10.1039/c2dt12017h

[79] X. Chen, Y. Wang, Y. Zhang, Z. Chen, Y. Liu, Z. Li, J. Li,Sensitive electrochemical aptamer biosensor for dynamic cell surface $\mathrm{N}$-glycan evaluation featuring multivalent recognition and signal amplification on a dendrimer-graphene electrode interface, Anal. Chem. 86(9) (2014)4278-4286. https://doi.org/10.1021/ac404070m

[80] X. Fang, J.F. Liu, J. Wang, H. Zhao, H.X. Ren, Z.X. Li, Dual signal amplification strategy of Au nanopaticles/ZnO nanorods hybridized reduced grapheme nanosheet and multi enzyme functionalized Au@ZnO composites for ultrasensitive electrochemical detection of tumor biomarker, Biosens. Bioelectron. 97 (2017)218225. https://doi.org/10.1016/j.bios.2017.05.055

[81] Y. Wang, C. Hou, Y. Zhang, F. He, M.Z. Liu, X.L. Li, Preparation of grapheme nano-sheet bonded PDA/MOF micro capsules with immobilized glucose oxidase as a mimetic multi-enzyme system for electrochemical sensing of glucose, J. Mater. Chem. B 4(21)(2016) 3695-3702. https://doi.org/10.1039/c6tb00276e

[82] C. Zhang, X.R. Wang, M. Hou, X.Y. Li, X.L. Wu, J. Ge, Immobilization on metalorganic framework engenders high sensitivity for enzymatic electrochemical detection, ACS Appl. Mater. Interfaces 9(16) (2017) 13831-13836.

https://doi.org/10.1021/acsami.7b02803

[83]F. Fu, Q. Wang, Removal of heavy metal ions from wastewaters: A review, Journal of Environmental Management 92 (2011) 407-418.

https://doi.org/10.1016/j.jenvman.2010.11.011

[84]N.K. Srivastava, C.B. Majumder, Novel biofiltration methods for the treatment of heavy metals from industrial wastewater, J. Hazard. Mater. 151 (2008) 1-8. 
[85] N. Tekaya, O. Saiapina, H. Ben Ouada, F. Lagarde, H. Ben Ouada, N.JaffrezicRenault, Ultra-sensitive conductometric detection of heavy metalsbased on inhibition of alkaline phosphatase activity from Arthrospiraplatensis, Bioelectrochemistry 90 (2013) 24-29. https://doi.org/10.1016/j.bioelechem.2012.10.001

[86] G.L. Turdean, Design and development of biosensors for the detection of heavy metal toxicity, Int. J. Electrochem. (2011) 1-15.

[87] W. S. Wan Ngah, M. A. K. M. Hanafiah, Removal of heavy metal ions from wastewater by chemically modified plant wastes as adsorbents: A review, Bioresour. Technol. 99 ( 2008) 3935-3948. https://doi.org/10.1016/j.biortech.2007.06.011

[88] A. Singh, R.K. Sharma, M. Agrawal, F.M. Marshall, Health risk assessment of heavy metals via dietary intake of food stuffs from the wastewater irrigated site of a dry tropical area of India, Food Chem. Toxicol. 48 (2010) 611-619. https://doi.org/10.1016/j.fct.2009.11.041

[89] C. Gao, X.Y. Yu, S.Q. Xiong, J.-H. Liu, X.J. Huang, Electrochemical detection of arsenic (III) completely free from noble metal: Fe3O4microspheres-roomtemperature ionic liquid composite showing better performance than gold, Anal. Chem. 85 (2013) 2673-2680. https://doi.org/10.1021/ac303143x

[90] K. Tag, K. Riedel, H.-J. Bauer, G. Hanke, K.H.R. Baronian, G. Kunze, Amperometric detection of $\mathrm{Cu} 2+$ by yeast biosensors using flow injection analysis (FIA),Sens. Actuators B: Chem. 122 (2007) 403-409. https://doi.org/10.1016/j.snb.2006.06.007

[91] X. Rajaganapathy, M.P. Sreekumar, Heavy metal contamination in soil,water and fodder and their presence in livestock and products: a review, J. Environ. Sci. Technol. 4 (2011) 234-249.

[92] M.R. Guascito, C. Malitesta, E. Mazzotta, A. Turco, Inhibitive determination of metal ions by an amperometric glucose oxidase biosensor, Sens. Actuators B:Chem. 131 (2008) 394-402. https://doi.org/10.1016/j.snb.2007.11.049

[93] M. Li, H. Gou, I. Al-Ogaidi, and N. Wu, Nanostructured Sensors for Detection of Heavy Metals: A Review, ACS Sustainable Chem. Eng. 2013, 1, 713-723. https://doi.org/10.1021/sc400019a

[94] K.E.Lorber, Monitoring of heavy metals by energy dispersive X-ray fluorescence spectrometry, Waste Manage. Res. 4 ( 1986) 3-13. https://doi.org/10.1177/0734242x8600400102

[95] R. Kunkel, S.E.Manahan, Atomic absorption analysis of strong heavy metal chelating agents in water and waste water, Anal. Chem 45(1973) 1465-1468. https://doi.org/10.1021/ac60330a024 
[96] M. Lopez-Artiguez, A. Cameán, M. Repetto, Preconcentration of heavy metals in urine and quantification by inductively coupled plasma atomic emission spectrometry, J. Anal. Toxicol. 17 (1993) 18-22. https://doi.org/10.1093/jat/17.1.18

[97] J. Wang, Stripping Analysis, VCH Publishers, New York, 1985.

[98] J. Buffle and M.L. Tercier-Waeber, Trends Anal. Chem., 24 (2005) 172.

[99] J. Wang, Analytical Electrochemistry, 3rd ed, Wiley, New York, 2006.

[100] O. K. Farha and J. T. Hupp, Rational design, synthesis, purification, and activation of metal-organic framework materials, Acc. Chem. Res. 43 (2010) 1166-1175. https://doi.org/10.1021/ar1000617

[101]. D. Zhao, D. J. Timmons, D. Q. Yuan and H. C. Zhou, Tuning the topology and functionality of metal-organic frameworks by ligand design, Acc.Chem. Res., 44 ( 2010) 123-133. https://doi.org/10.1021/ar100112y

[102] B. Seoane, J. Coronas, I. Gascon, M. Etxeberria Benavides, O. Karvan, J. Caro, F. Kapteijnand J. Gascon, Metal-organic framework based mixed matrix membranes: a solution for highly efficient $\mathrm{CO}_{2}$ capture? Chem. Soc. Rev. 44 (2015) 2421-2454. https://doi.org/10.1039/c4cs00437j

[103]. J. L. C. Rowsell and O. M. Yaghi, Effects of functionalization, catenation, and variation of the metal oxide and organic linking units on the low-pressure hydrogen adsorption properties of metal-organic frameworks, J. Am. Chem. Soc. 128 (2006) 1304-1315. https://doi.org/10.1021/ja056639q

[104] K. Schlichte, T. Kratzke and S. Kaskel, Improved synthesis, thermal stability and catalytic properties of the metal-organic framework compound $\mathrm{Cu}_{3}(\mathrm{BTC})_{2}$, MicroporousMesoporous Mater.73 (2004) 81-88. https://doi.org/10.1016/j.micromeso.2003.12.027

[105] B. Liu and B. Smit, Comparative Molecular simulation study of $\mathrm{CO}_{2} / \mathrm{N}_{2}$ and $\mathrm{CH}_{4} / \mathrm{N}_{2}$ Separation in zeolites and metal-organic frameworks, J. Am. Chem. Soc. 25 (2009) 5918-5926. https://doi.org/10.1021/la900823d

[106] Y. Wang, H. Ge, G. Ye, H. Chen and X. Hu, Carbon functionalized metal organic framework/ Nafion composites as novel electrode materials for ultrasensitive determination of dopamine, J. Mater. Chem. B 3 (2015) 3747-3753. https://doi.org/10.1039/c4tb01869a

[107] Z. Xu, L. Yang and C. Xu, Pt@UiO-66 heterostructures for highly selective detection of hydrogen peroxide with an extended linear range, Anal. Chem. 87 (2015) 3438-3444. https://doi.org/10.1021/ac5047278

[108] Y. Wang, L. Wang, H. Chen, X. Hu and S. Ma, Fabrication of highly sensitive and stable hydroxylamine electrochemical sensor based on gold nanoparticles and metal- 
metalloporphyrin framework modified electrode, ACS Appl. Mater. Interfaces 8 (2016) 18173-18181. https://doi.org/10.1021/acsami.6b04819

[109] Y. Zhang, X. Bo, C. Luhana, H. Wang, M. Li and L. Guo, Facile synthesis of a Cubased MOF confined in macroporous carbon hybrid material with enhanced electrocatalytic ability, Chem.Commun.49 (2013) 6885-6887. https://doi.org/10.1039/c3cc43292k

[110] X. Fang, B. Zong and S. Mao, Metal-Organic Framework-Based Sensors for Environmental Contaminant Sensing, Nano-Micro Lett. 10 (2018) 64. https://doi.org/10.1007/s40820-018-0218-0

[111] Y.J. Yu, C. Yu, Y.Z. Niu, J. Chen, Y.L. Zhao, Y.C. Zhang, R.F.Gao, J.L. He, Target triggered cleavage effect of DNAzyme: relying on Pd-Pt alloys functionalized Fe-MOFs for amplified detection of $\mathrm{Pb}^{2+}$, Biosens. Bioelectron. 101 (2018) 297-303. https://doi.org/10.1016/j.bios.2017.10.006

[112] H.X. Guo, D.F. Wang, J.H. Chen, W. Weng, M.Q. Huang, Z. S. Zheng, Simple fabrication of flake-like $\mathrm{NH}_{2}$-MIL-53(Cr) and its application as an electrochemical sensor for the detection of $\mathrm{Pb}^{2+}$, Chem. Eng. J. 289 (2016) 479-485. https://doi.org/10.1016/j.cej.2015.12.099

[113] J.C. Jin, J. Wu, G.P. Yang, Y.L. Wu, Y.Y. Wang, A microporous anionic metalorganic framework for a highly selective and sensitive electrochemical sensor of $\mathrm{Cu}^{2+}$ ions. Chem. Commun. 52 (2016) 8475-8478. https://doi.org/10.1039/c6cc03063g

[114] J. C. Jin, J. Wu, G. P. Yang, Y. L. Wua and Y. Y. Wang, A microporous anionic metal-organic framework for highly selective and sensitive electrochemical sensor of $\mathrm{Cu}^{2+}$ ion, Electronic Supplementary Material (ESI) for Chem. Comm. J.

[115] M. Saraf, R. Rajak, S.M. Mobin, A fascinating multitasking Cu-MOF/rGO hybrid for high performance supercapacitors and highly sensitive and selective electrochemical nitrite sensors, J. Mater. Chem. A 4, 42 (2016)16432-16445. https://doi.org/10.1039/c6ta06470a

[116] D. A. Perry, T. M. Razer, K. M. Primm, T. Chen, J. B. Shamburger et al., Surfaceenhanced infrared absorption and density functional theory study of dihydroxybenzene isomer adsorption on silver nanostructures, J. Phys. Chem. C 117(16) (2013) 81708179. https://doi.org/10.1021/jp3121462

[117] Y. Yang, Q. Wang, W. Qiu, H. Guo, F. Gao, Covalent immobilization of $\mathrm{Cu}_{3}(\mathrm{btc})_{2}$ at chitosan-electro reduced grapheme oxide hybrid film and its application for simultaneous detectionof dihydroxybenzene isomers, J. Phys. Chem. C 120(18)(2016)9794-9803. https://doi.org/10.1021/acs.jpcc.6b01574 
[118] X. Zhou, X. Yan, Z. Hong, X. Zheng, F. Wang, Design of magnetic core-shell Ni@graphene composites as a novel electrochemical sensing platform, Sens. Actuators B-Chem. 255(2018)2959-2962. https://doi.org/10.1016/j.snb.2017.09.117

[119] J. Li, J. Xia, F. Zhang, Z. Wang, Q. Liu, An electrochemical sensor based on copper-based metal-organic frameworks-graphene composites for determination of dihydroxybenzene isomers in water, Talanta 181 (2018) 80-86. https://doi.org/10.1016/j.talanta.2018.01.002

[120] S.S. Huang, Y.X. Qu, R.N. Li, J. Shen, L.W. Zhu, Biosensor based on horseradish peroxidase modified carbon nanotubes for determination of 2,4dichlorophenol,Microchim. Acta., 162 (1-2) (2008) 261-268. https://doi.org/10.1007/s00604-007-0872-2

[121] S. Dong, G. Suo, N. Li, Z. Chen, L. Peng, Y. Fu, Q. Yang, T. Huang, A simple strategy to fabricate high sensitive 2,4-dichlorophenol electrochemical sensor based on metal organic framework $\mathrm{Cu}_{3}(\mathrm{BTC})_{2}$, Sens. Actuators B-Chem. 222 (2016) 972-979. https://doi.org/10.1016/j.snb.2015.09.035

[122] Y. Wang, Y.C. Wu, J. Xie, X.Y. Hu, Metal-organic framework modified carbon paste electrode for lead sensor. Sens. Actuators B-Chem. 177 (2013) 1161-1166. https://doi.org/10.1016/j.snb.2012.12.048

[123] J. Yang, L.T. Yang, H.L. Ye, F.Q. Zhao, B.Z. Zeng, Highly dispersed Au-Pd alloy nanoparticles immobilized on UiO-66- $\mathrm{NH}_{2}$ metal-organic framework for the detection of nitrite. Electrochim. Acta 219 (2016) 647-654. https://doi.org/10.1016/j.electacta.2016.10.071

[124]. J. Zhou, X. Li, L.L. Yang, S.L. Yan, M.M. Wang et al., The Cu-MOF-199/singlewalled carbon nanotubes modified electrode for simultaneous determination of hydroquinone and catechol with extended linear ranges and lower detection limits. Anal. Chim. Acta 899 (2015) 57-65. https://doi.org/10.1016/j.aca.2015.09.054 